Public Choice 85: 91-105, 1995.

(c) 1995 Kluwer Academic Publishers. Prinied in the Netherlands.

\title{
Do welfare benefits cause the welfare caseload?
}

\author{
PARTH J. SHAH \\ PATRICIA K. SMITH \\ Department of Social Sciences, University of Michigan-Dearborn, Dearborn, MI 48128
}

Accepted 24 November 1993

\begin{abstract}
Analyses of the welfare system generally examine one of five competing models: (1) The work disincentive model; (2) the human capital model; (3) the macroeconomic model; (4) the public choice model; or (5) the cost-of-job-loss model. This paper employs the Granger causality concept and the multiple-rank F statistic to test the implications of all five of these models simultaneously. The results offer modest support to all but the macroeconomic model. The relationships among welfare benefits, caseloads, and labor market conditions appear to be too complex to be fully captured by a single model.
\end{abstract}

\section{Introduction}

Since the inception of public assistance programs, critics have argued that offering benefits, however well-intended, would reward and thus create poverty. For example, after visiting England and reviewing its Poor Laws, Benjamin Franklin (1776) commented, "In short, you offered a premium for the encouragement of idleness, and you should not now wonder that it has had its effect in the increase in poverty."

Many social scientists have investigated this work disincentive hypothesis. For example, Moffitt (1987) analyzes cross-sectional data and finds that higher AFDC guarantee levels are associated with a greater likelihood of welfare participation. Duncan (1984) analyzes panel data and finds that most welfare recipients receive benefits for only a short period of time and typically join the welfare rolls following a change in family composition (e.g., divorce or birth of a child). Murray (1984) presents time series plots which show that the number of mother-only families and the welfare caseload have both increased since the War on Poverty began, suggesting that the expansion of welfare created more poverty.

Examination of all types of data on welfare variables is important; however, visual comparison of time series plots hardly constitutes rigorous analysis. More sophisticated time series techniques are available; for example, macroeconomists have used testable causality concepts quite fruitfully in the study of money, income, and prices (e.g., Sims 1972, Holmes and Hutton, 1992). 
Welfare analysts generally rely on cross-sectional or panel data and thus rarely employ such time series techniques. ${ }^{1}$ This omission creates a gap in the analysis of the effects of welfare benefits - a useful analytical tool has been overlooked. Causality tests could improve our understanding of the relationship between welfare benefits, caseloads, and labor market conditions over time. While these tests are not perfect and new techniques are still evolving, they do provide the best available evidence on causality when controlled experiments are not possible.

Granger causality tests determine whether past values of a variable $X$ significantly improve the forecast of the current value of another variable $Y$. If information on past $\mathrm{X}$ is a statistically significant predictor of current $\mathrm{Y}$ then $\mathrm{X}$ "Granger-causes" $Y$. That is, the Granger test identifies a variable $X$ as causal if changes in $\mathrm{X}$ both precede and are significant predictors of changes in another variable $\mathrm{Y}$. Philosophically this is a limited concept of causality; it is, however, a testable concept.

A basic technical criticism of Granger causality tests is that the standard Ftest of joint significance, upon which the test relies, can be misleading in the presence of nonlinearities and heteroscedastic errors. Consequently we employ an alternative test statistic, the multiple-rank $F$ statistic, as suggested by Holmes and Hutton (1992). This non-parametric test statistic results from standard regression analysis of ranked, rather than raw, data. Monte Carlo studies show that this test statistic is less sensitive to error distribution and nonlinearities. The present analysis uses this test statistic and the Granger-causality concept to test formally for causal patterns among AFDC benefits, the AFDC caseload, the unemployment rate, and average earnings in Michigan. The focus on one state avoids the aggregation bias inherent in analysis of national averages. Of particular interest is whether AFDC benefits cause, in the Granger sense, the AFDC caseload.

The paper is organized as follows. Section 1 presents the work disincentive model as well as four competing models of the welfare caseload. Each model's predicted patterns of causality are identified. For example, if the work disincentive hypothesis is correct we would observe that benefits cause the caseload. Section 2 describes the methodology and the data. Section 3 reports the results of the causality tests. Section 4 presents a summary and conclusions.

\section{Models of the welfare caseload}

Prior studies typically examine one of five competing models of the welfare caseload: (1) The work disincentive model; (2) the human capital model; (3) the macroeconomic model; (4) the public choice model; and (5) the cost-of-jobloss model. First, the work disincentive hypothesis derives from a simple 
model of individual choice. An individual chooses between work, which generates earned income and decreases leisure time, and nonwork, which can generate unearned (welfare) income and increases leisure time. The individual will choose the state, work or welfare, which yields the highest expected utility. We can represent the individual's choice with the dichotomous variable WELFARE:

WELFARE $=\left\{\begin{array}{l}\left.0 \text { if U(EARN, LEISURE, } E_{e}\right)>U\left(B E N, \text { LEISURE, } E_{w}\right) \\ \left.1 \text { if U(EARN, LEISURE, } E_{e}\right)<U\left(B E N, \text { LEISURE, } E_{w}\right)\end{array}\right.$

where EARN is real earnings, BEN is the real welfare benefit, and the E's represent unobservable random values or tastes regarding work and welfare. The work disincentive hypothesis focuses on the implication that, ceteris paribus, the higher are welfare benefits, the higher is the utility from welfare and thus the more likely the individual is to choose nonwork and welfare receipt. Increases in welfare benefits will consequently cause increases in the welfare caseload and perhaps increases in the unemployment rate.

Analyses of the two components of the AFDC benefit formula, the guarantee and the implicit tax rate (or benefit reduction rate), also predict that higher benefits will lead to increases in the caseload and reductions in labor supply. Danziger et al. (1981) survey the literature on the labor supply effects of welfare and conclude that welfare benefits cause a small decrease in labor supply. The authors note that reductions in the implicit tax rate raise the breakeven level of income, making more people eligible for benefits. Thus, reducing this tax rate will raise benefits and increase the caseload via a purely mechanical response. Thus, a finding that benefits Granger-cause the caseload is consistent with both the work disincentive model and this mechanical response.

Second, the human capital model notes that the model of individual choice (1) also implies that increases in earnings will increase the utility from work and will thus lower the likelihood that the individual will choose nonwork and welfare receipt, ceteris paribus. This model predicts that higher earnings will cause the welfare caseload to fall. Thus, causality flows from earnings to the caseload. There is some cross-sectional evidence in support of this model. Moffitt (1983), using 1975 data, finds that the wage rate and the AFDC participation rate are negatively related.

The individual choice analysis yields two different implications which suggest radically different policies. The work disincentive implication suggests that reducing welfare benefits will reduce caseloads and increase labor force participation and employment. The human capital implication suggests that instead of reducing welfare benefits, education and training programs designed to increase earnings will cause decreases in unemployment and the caseload. 
The third model, the macroeconomic model, emphasizes the role of trends in unemployment on the welfare caseload. Unemployment, and the ensuing poverty, may not be a matter of personal choice; individuals may be involuntarily unemployed or may withdraw from the labor force as a result of adverse regional or national macroeconomic trends. For example, Moffitt (1983) finds that the probability of welfare participation rises as the unemployment rate increases. Bassi (1990) reports that the increase in women's welfare receipt during the 1970's resulted in part from an increase in their involuntary unemployment. ${ }^{2}$ In this view, unemployment causes welfare caseloads. Macroeconomic policies designed to stimulate job growth could reduce welfare caseloads.

The models thus far ignore the fact that both the level of benefits and eligibility criteria result from collective choices at the federal and state levels of government. Public choice theory predicts that significant increases in the number of poor and welfare dependent could lead to increases in welfare benefits. A significant increase in the number of poor relative to the number of nonpoor could alter the distribution of voters as identified by income. ${ }^{3}$ The resulting distribution would have a lower income median voter. A poorer median voter may have a greater incentive to vote for higher welfare benefits. Thus, the caseload could cause the benefit level.

There has been some concern about the claim that increases in the welfare caseload could increase the power of recipients as a voting bloc. Voter turnout among the poor has historically been low, and, as Olson (1971) explains, the larger and more diverse the group, the more difficult it is to form an effective lobby. It seems unlikely then that recipient could use their political power to gain increases in welfare benefits.

Leffler (1978) suggests that welfare bureaucracies and labor unions, rather than the poor themselves, tend to form pro-welfare lobbies. A greater welfare caseload generally implies a more sophisticated welfare bureaucracy, whose members may lobby for its expansion. Labor unions may also support more generous welfare benefits in order to reduce competition for union jobs. Anderson (1987) finds that the level of AFDC payments is highly and positively correlated with the political power held by organized labor. The more poor, the greater the threat to union jobs, and the more likely is organized labor to lobby for generous welfare benefits and eligibility criteria. The greater the welfare caseload, the stronger will be union lobbying efforts to increase welfare benefits. Again, public choice theory predicts that caseloads cause the benefit level.

The fifth and final model derives from Bowles (1985) and Schor and Bowles (1987), which argue that the unemployment rate affects the negotiating power of workers relative to employers. Schor and Bowles (1987) suggest that high unemployment strengthens employers' negotiating power and ability to extract labor from workers. If workers must risk long periods of unemployment they 
Table 1. Predicted causal patterns

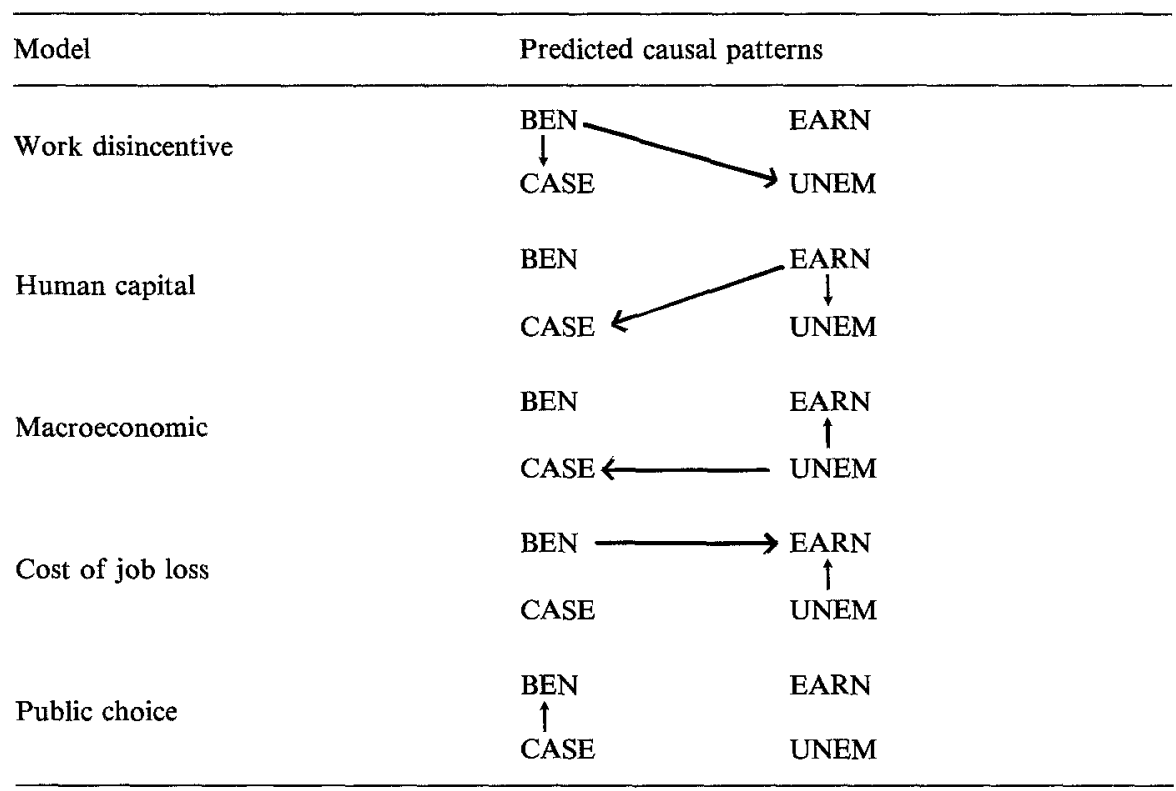

are less likely to shirk, demand higher wages, or strike. Thus, high unemployment will exert downward pressure on wages and earnings. Conversely, when unemployment is low workers risk only short term unemployment and are subsequently more likely to shirk, demand higher wages, or strike. In short, the cost of losing one's job is inversely related to worker demands. If true, we would expect to find that the unemployment rate causes earnings.

More generous welfare benefits reduce the cost of job loss and thus increase workers' negotiating power. The cost-of-job-loss model thus also predicts that increases in the welfare benefit level will cause wages and earnings to increase. In addition, expansion of welfare will countervail the depressing effects of unemployment on wages. In short, this model predicts that welfare benefits cause earnings and that benefits may lessen the effect of unemployment on earnings.

The five models predict very different causal patterns among welfare benefits, caseloads, earnings and the unemployment rate. Table 1 summarizes the causal patterns for each model. The task at hand is to determine which, if any, of these patterns are consistent with the data.

\section{Methodology and data}

Many earlier studies of the welfare caseload focus on one of the five models presented and test only whether or not that model's implications are empirically supported. Consequently the possibility that more than one model contrib- 
utes to the understanding of the caseload is precluded. The Granger causality test requires only a very general autoregressive model structure which allows us to test the implications of all five models simultaneously.

Most prior research on the welfare caseload uses cross-sectional or panel data. Cross-sectional data cannot reveal the true dynamic nature of the caseload generation process. Panel data can capture the dynamic process, however the number of observations (time periods) available in most panel data sets is fairly limited. Murray (1984) and Moffitt (1987) both use annual data to analyze caseloads and welfare participation, but both rely on simple visual inspection of trends. Moffitt admits that such techniques are "extremely crude, and it would be desirable to conduct a more formal statistical examination ..." The Granger causality test provides the technique for such formal statistical analysis.

This section reviews the Granger causality concept and the associated time series techniques for testing such causality. We begin with a simple bivariate example and then expand the analysis to our multivariate system.

Granger (1969) proposes that $X_{t}$ "causes" $Y_{t}$ if information on past and present $\mathrm{X}_{\mathrm{t}}$ significantly improves the forecast of $\mathrm{Y}_{\mathrm{t}}{ }^{4}$ Formally, let a stationary, normally distributed bivariate autoregressive process of order $p$ generate $X_{t}$ and $Y_{t}$ :

$$
\begin{aligned}
& X_{t}=a_{11}(L) X_{t}+a_{12}(L) Y_{t}+E_{1 t} \\
& Y_{t}=a_{21}(L) X_{t}+a_{22}(L) Y_{t}+E_{2 t}
\end{aligned}
$$

where $L$ denotes the lag operator $(L=1, \ldots p)$. Assuming past and present $X_{t}$ and $Y_{t}$ represent all relevant information, $X_{t}$ Granger-causes $Y_{t}$ if the $\hat{a}_{21}(L)$ differ significantly from zero. If both the $\hat{a}_{21}(L)$ and $\hat{a}_{12}(L)$ are nonzero, there is feedback between the two variables: $X_{t}$ and $Y_{t}$ simultaneously cause each other. Note that this only tests the ability of past and current $X_{t}$ to predict current $Y_{t}$, which, in a strict philosophical sense, differs from the notion that $X_{t}$ causes $Y_{t}$. For the sake of exposition however, we use the term "causes" to denote that a variable "Granger-causes" another throughout the remainder of the paper.

To conduct Granger causality tests of the hypothesized patterns identified in Section 1 we estimate systems of the following general form:

$$
\begin{aligned}
& \text { BEN }_{t}=a_{11}(L) \text { BEN }_{t}+a_{12}(L) \text { CASE }_{t}+a_{13}\left(L^{\prime}\right) \text { UNEM }_{t}+a_{14}(L) \text { EARN }_{t}+e_{1 t} \\
& \text { CASE }_{\mathrm{t}}=\mathrm{a}_{21}(\mathrm{~L}) \text { CASE }_{\mathrm{t}}+\mathrm{a}_{22}(\mathrm{~L}) \mathrm{BEN}_{\mathrm{t}}+\mathrm{a}_{23}(\mathrm{~L}) \mathrm{UNEM}_{\mathrm{t}}+\mathrm{a}_{24}(\mathrm{~L}) \mathrm{EARN}_{\mathrm{t}}+\mathrm{e}_{2 \mathrm{t}} \\
& \mathrm{UNEM}_{\mathrm{t}}=\mathrm{a}_{31}(\mathrm{~L}) \mathrm{UNEM}_{\mathrm{t}}+\mathrm{a}_{32}(\mathrm{~L}) \mathrm{CASE}_{\mathrm{t}}+\mathrm{a}_{33}(\mathrm{~L}) \mathrm{BEN}_{\mathrm{t}}+\mathrm{a}_{34}(\mathrm{~L}) \mathrm{EARN}_{\mathrm{t}}+\mathrm{e}_{3 \mathrm{t}} \\
& \text { EARN }_{t}=a_{41}(L) \text { EARN }_{t}+a_{42}(L) C_{\text {CASE }}+a_{43}(L) \text { UNEM }_{t}+a_{44}(L) \text { BEN }_{t}+e_{4 t}
\end{aligned}
$$


where:

$\mathrm{L}=$ the lag operator

$\mathrm{BEN}=$ the real AFDC benefit

CASE = the AFDC caseload

UNEM = the unemployment rate

$\mathrm{EARN}=$ the real weekly earnings

If benefits cause the caseload, as predicted by the work disincentive model, the $\hat{a}_{22}$ will be jointly significantly different from zero. If, on the other hand, the unemployment rate alone drives the caseload the $\hat{a}_{22}$ will not differ from zero, but the $\hat{a}_{23}$ will.

The data are monthly observations of Michigan averages beginning with January 1970 and ending with August 1992. ${ }^{5}$ The focus on one state avoids the aggregation bias inherent in analysis of national averages. We employ two measures of the AFDC caseload: the number of cases (CASE) and the number of individuals receiving AFDC benefits (RECIP). Benefits (BEN) are accordingly measured as either the real AFDC benefit per case (CBEN) or per individual recipient (RBEN). ${ }^{6}$ Food Stamps are generally considered to be nearmoney and data on the average value of Food Stamps per recipient is available. ${ }^{7}$ Thus we also use the combined AFDC and Food Stamps benefit per recipient (TBEN) as a measure of welfare benefits. ${ }^{8}$ We measure earnings (EARN) as the weekly average real earnings of Michigan manufacturing workers. The appendix describes these data and lists the sources.

Causality tests require that each time series, or variable, be stationary. A time series can be made stationary either by including a time variable or by differencing the data, depending on the structure of the series. Nelson and Kang (1984) detail the problems of "spurious trend" and of detrending by inclusion of a time variable when the difference procedure is required. Following Nelson and Plosser (1982), we determine whether each variable is a trendstationary process (TSP) or a difference-stationary process (DSP) by estimating the equation:

$$
Y_{t}=a+b Y_{t-1}+c T+e_{t}
$$

where $Y_{t}$ is the variable in natural logs and $T$ is a time trend variable. If $b=1$ and $c=0$, then the variable is a difference-stationary process (DSP class) and can be made stationary by differencing. If $b<1$, then the variable follows a time-stationary process (TSP class) and can be made stationary by including a time variable. We use the Dickey and Fuller (1981) likelihood ratio to test the hypothesis $b=1$ and $c=0$ against the hypothesis that $b<1$. All variables in this analysis belong to the TSP class. To induce stationarity we simply include 
a time trend variable $(\mathrm{T})$ in all regressions. A constant term is also included to assure that the stationary series have zero means.

Holmes and Hutton (1988) show that if $\mathrm{Y}$ is a function of $\mathrm{X}$, any strictly monotonic transformation of $\mathrm{Y}$ and/or $\mathrm{X}$ (e.g., ranking) will not destroy the functional relationship. Regression on ranked variables will generate a multiple-rank $F$ test rather than a standard parametric $F$ test. Conover and Iman (1982) and Olejnik and Algina (1985) conduct Monte Carlo studies of the multiple-rank $F$ test and find that in small samples this non-parametric test is robust in the presence of non-normal errors. Also, the power of this test over the parametric F statistic improved in cases where the error structure was nonnormal and heteroscedastic.

Each variable and its lags are treated as separate variables when transforming the data into ranks. Consequently 96 new variables must be created - the first through twenty-fourth lags of each of the original four variables: BEN, CASE, UNEM, and EARN. The four original variables and all of the lagged variables are then transformed into their ranks (the mean rank is assigned in the case of ties). Equation (3) will then be estimated using the variables in ranks and will thus generate a multiple-rank $F$ test statistic. The analysis will use this statistic to test for the joint significance of a variable's set of lags, i.e. to test for Granger causality.

Before the system described by equation (3) can be estimated the appropriate lag lengths for each ranked variable must be determined. For each variable (in ranks) we estimate a series of autoregressive processes, with lag length varying from one to twenty-four. There are various criteria available to determine which of the lag lengths is optimal and frequently different criteria indicate different lag lengths (Geweke and Meese, 1981 and Thorton and Batten, 1985). We consider three criteria: Akaike's criterion (AIC); Amemiya's final prediction error (FPE); and the Schwarz criterion (SC). In all but one case the FPE and AIC select the same lag length. The SC indicates the shortest lag length in all cases. Because the Schwarz criteria tends to underestimate the true lag order, we choose the lag indicated by the FPE and AIC (Choi, 1992). In the one case where the FPE and AIC criteria indicate different lag orders we choose the order indicated by the FPE as this criterion will also be used in determining causal ordering in the multivariate model. ${ }^{9}$

Once the appropriate own-lag lengths are determined we estimate bivariate regressions of a variable on its own lags and on lags of one of the model's other variables. Following the specific gravity criterion of Caines, Keng, and Sethi (1981), the variable with the minimum FPE among the all the autoregressive equations is added first. An equation of the variable on its own-lags and on the lags of the added variable is then estimated, letting the order of the latter lag vary from one to twenty-four. The FPE and AIC again indicate the appropriate lag for the second variable. The third and fourth variables are added and their lag orders are similarly determined. 
After selecting the appropriate variable ordering and lag lengths we pool the four equations (BEN, CASE, UNEM, and EARN) to form a system, which is re-estimated by the maximum likelihood procedure. This procedure accounts for possible cross-equation error correlation. F-tests of the joint significance of the coefficients on each variable's set of lags are then performed to infer whether or not a given variable causes the dependent variable. Three systems are estimated, each using one of the three different measures of the benefit (AFDC benefit per case, AFDC benefit per recipient, and combined AFDC and Food Stamps benefits per recipient):

$$
\begin{aligned}
& \text { CBEN }_{t}=a_{o}+a_{11}(13) \text { CBEN }_{t}+a_{12}(4) \text { CASE }_{t}+a_{13}(1) \operatorname{UNEM}_{t}+a_{14}(1) E \text { ARN }_{t}+b_{1} T+e_{1 t} \\
& \text { CASE }_{t}=a_{0}+a_{21}(14) \text { CASE }_{t}+a_{22}(2) \text { CBEN }_{t}+a_{23}(3) \text { UNEM }_{t}+a_{24}(8) \text { EARN }_{t}+b_{2} T+e_{2 t} \\
& \text { UNEM }_{t}=a_{o}+a_{31}(15) \text { UNEM }_{t}+a_{32}(1) \text { CASE }_{t}+a_{33}(1) \text { CBEN }_{t}+a_{34}(3) \text { EARN }_{t}+b_{3} T+e_{3 t} \\
& \text { EARN }_{t}=a_{0}+a_{41}(14) \text { EARN }_{t}+a_{42}(5) C_{A S E}+a_{43}(1) C_{1} \text { CEN }_{t}+a_{44}(9) U N E M_{t}+b_{4} T+e_{4 t} \\
& \text { RBEN }_{t}=a_{o}+a_{11}(14) \text { RBEN }_{t}+a_{12}(1) \operatorname{RECIP}_{\mathfrak{t}}+a_{13}(2) \operatorname{UNEM}_{t}+a_{14}(1) \text { EARN }_{t}+b_{1} T+e_{1 t} \\
& \text { RECIP }_{t}=a_{o}+a_{21}(14) \text { RECIP }_{t}+a_{22}(13) \text { RBEN }_{t}+a_{23}(1) \text { UNEM }_{t}+a_{24}(2) \text { EARN }_{t}+b_{2} T+e_{2 t} \\
& \text { UNEM }_{t}=a_{o}+a_{31}(15) U_{N E M}+a_{32}(1) \operatorname{RECIP}_{t}+a_{33}(5) \operatorname{RBEN}_{t}+a_{34}(3) \text { EARN }_{t}+b_{3} T+e_{3 t} \\
& \text { EARN }_{t}=a_{o}+a_{41}(14) E_{A R N}+a_{42}(1) \operatorname{RECIP}_{t}+a_{43}(1) \operatorname{RBEN}_{t}+a_{44}(4) \operatorname{UNEM}_{t}+b_{4} T+e_{4 t}
\end{aligned}
$$

where UNEM and EARN are as previously defined and:

CBEN = real AFDC benefit per case

RBEN = real AFDC benefit per recipient

TBEN = real combined AFDC and Food Stamp benefit per recipient

$\mathrm{T}=$ time trend variable

(k) = the optimal number of lags

\section{Results}

The first estimated system uses the number of AFDC cases to measure the welfare caseload (equation 5). Table 2 reports the observed multiple-rank $F$ statistic for the joint significance of the coefficients on each variable's set of lags. For example, in the benefit equation the test statistic for the joint significance of CASE $(t-1)$ through CASE $(t-4)$ is 3.73 . The critical value for the $99 \%$ level of significance is 3.38 , thus there is evidence that the AFDC caseload causes the benefit level. This result is consistent with the public choice model.

The results indicate three additional causal patterns. First, earnings and the 
Table 2. Results of causality tests

\begin{tabular}{|c|c|c|c|c|c|c|}
\hline \multicolumn{2}{|c|}{$\begin{array}{l}\text { AFDC benefits } \\
\text { per case }\end{array}$} & \multicolumn{3}{|c|}{$\begin{array}{l}\text { Multiple rank F } \\
\text { statistic }\end{array}$} & \multicolumn{2}{|l|}{$\begin{array}{l}\text { Causal } \\
\text { patterns }\end{array}$} \\
\hline & CBEN & CASE & UNEM & EARN & & \\
\hline \multicolumn{7}{|l|}{ dep. } \\
\hline CBEN & - & $3.73^{\mathrm{a}}$ & 1.73 & 0.025 & \multirow{4}{*}{$\begin{array}{c}\text { BEN } \\
\stackrel{\text { CASE }}{1}\end{array}$} & \multirow{4}{*}{$\begin{array}{c}\text { EARN } \\
\vdots \\
\text { UNEM }\end{array}$} \\
\hline CASE & 0.538 & - & 0.725 & $3.67^{\mathrm{a}}$ & & \\
\hline UNEM & 2.34 & $3.07 \mathrm{c}$ & - & $15.61^{\mathrm{a}}$ & & \\
\hline EARN & 1.93 & $3.28^{\mathrm{a}}$ & $4.61^{a}$ & - & & \\
\hline \multicolumn{2}{|c|}{$\begin{array}{l}\text { AFDC benefits } \\
\text { per recipient }\end{array}$} & \multicolumn{3}{|c|}{$\begin{array}{l}\text { Multiple rank F } \\
\text { statistic }\end{array}$} & \multicolumn{2}{|l|}{$\begin{array}{l}\text { Causal } \\
\text { patterns }\end{array}$} \\
\hline & RBEN & RECIP & UNEM & EARN & & \\
\hline \multicolumn{7}{|l|}{ dep. } \\
\hline RBEN & - & 1.45 & 1.85 & 0.025 & \multirow{4}{*}{$\begin{array}{c}\text { BEN } \\
1 \\
\text { RECIP }\end{array}$} & \multirow{4}{*}{$\begin{array}{c}\text { EARN } \\
\vdots \\
\text { UNEM }\end{array}$} \\
\hline RECIP & $4.31^{\mathrm{a}}$ & - & 1.47 & $9.71^{\mathrm{a}}$ & & \\
\hline UNEM & 1.57 & 1.37 & - & $9.49^{\mathrm{a}}$ & & \\
\hline EARN & 2.43 & $8.65^{\mathrm{a}}$ & $7.77^{\mathrm{a}}$ & - & & \\
\hline \multicolumn{2}{|c|}{$\begin{array}{l}\text { AFDC + Food Stamps } \\
\text { benefits per recipient }\end{array}$} & \multicolumn{2}{|c|}{$\begin{array}{l}\text { Multiple rank F } \\
\text { statistic }\end{array}$} & & \multicolumn{2}{|l|}{$\begin{array}{l}\text { Causal } \\
\text { patterns }\end{array}$} \\
\hline & TBEN & RECIP & UNEM & EARN & & \\
\hline \multicolumn{7}{|l|}{ dep. } \\
\hline TBEN & - & 0.0014 & 0.0283 & 1.95 & \multirow{4}{*}{$\begin{array}{c}\text { BEN } \\
\downarrow \\
\text { RECIP }\end{array}$} & \multirow{4}{*}{$\begin{array}{c}\text { EARN } \\
1 \\
\text { UNEM }\end{array}$} \\
\hline RECIP & $3.34^{a}$ & - & 1.79 & 2.18 & & \\
\hline UNEM & 0.392 & 0.2912 & - & $10.14^{\mathrm{a}}$ & & \\
\hline EARN & $2.09 \mathrm{a}$ & 0.7446 & $5.67^{\mathrm{a}}$ & - & & \\
\hline
\end{tabular}

a significant at the $99 \%$ level.

${ }^{b}$ significant at the $95 \%$ level.

c significant at the $90 \%$ level.

unemployment rate simultaneously cause each other. Causality running from the unemployment rate to earnings is consistent with the cost-of-job-loss model. The feedback from earnings to unemployment has more to do with labor markets than with welfare programs. Second, the caseload and earnings also simultaneously cause each other. The human capital model predicts part of this pattern as it implies that earnings cause the caseload. The observed feedback from the caseload to earnings may result from a reduced (increased) supply of labor when the welfare caseload increases (decreases). It may also result because higher caseloads imply more persons with low or no earnings, which would lower average earnings.

Lastly, the results from the first system indicate that the caseload causes the unemployment rate (at the $\mathbf{9 0 \%}$ level). This could result simply due to the formula for calculating the unemployment rate. The more adult recipients with 
young children, and thus exempt from work requirements, the fewer adults there will be actively seeking work. The fewer adults seeking employment, the lower is the unemployment rate's denominator, ceteris paribus, and thus the higher the unemployment rate. Alternatively, it could be that in order to join the welfare roles adults, particularly those with older children, claim to be unemployed.

Next, the system using the number of AFDC recipients to measure the caseload and benefits per recipient to measure benefits is estimated (equation 6). As in the previous system, there is evidence that earnings and the caseload simultaneously cause each other. This result offers some support for the human capital model. Again the unemployment rate and earnings exhibit mutual causation, which offers some support for the cost-of-job loss model.

The "per recipient" system differs from the "per case" system in two important ways. First, unlike the "per case" system there is no evidence that the caseload measured by the number of recipients causes the unemployment rate. This difference may result because the number of recipients is less closely tied to the number of adults than is the number of AFDC cases (the majority of recipients are children). Second, benefits per caseload do not appear to cause the number of AFDC cases, but benefits per recipient appear to cause the number of recipients. The latter result is consistent with both the work disincentive model and the mechanics of the benefit reduction rate inherent in the AFDC program.

Because most AFDC recipients also receive Food Stamps a third system using the combined benefits per recipient to measure benefits is estimated (equation 7).$^{10}$ As in the two previous systems, there is evidence that earnings and the unemployment rate simultaneously cause each other. Similar to the "per recipient"' system there is evidence that the combined benefits cause the number of AFDC recipients. In contrast to the two previous systems, there is no evidence of mutual causation between earnings and the number of recipients. Instead there is evidence that the combined benefit causes earnings. This result is consistent with the cost-of-job-loss model.

\section{Summary and conclusions}

This paper has employed the most up-to-date techniques for testing causality with time series data to examine the relationships between welfare benefits, the welfare caseload, the unemployment rate, and earnings. These techniques allow us to test the implications of five basic models of the welfare caseload. The results offer limited support for four of the five models.

The primary hypothesis to be tested is whether AFDC benefits cause the AFDC caseload. The results offer some support for this hypothesis: Benefits 
per recipient cause the number of recipients. This result is consistent with both the work disincentive model and with the mechanical relationship between eligibility limits and the implicit tax on benefits.

Benefits per case, however, do not cause the number of cases. Instead, the number of cases appear to cause benefits per case. We have no definitive explanation for this difference yet. Perhaps because the caseload is more closely linked to the number of adult recipients and thus the number of potential voters and earners, the public choice model receives support only when the caseload is measured per case.

Another possible explanation is that the per recipient measure is picking up the effect of benefit levels on family size. Welfare critics have expressed concern that benefits may encourage poor women to have more children, increasing the number of recipients. This seems highly unlikely, however, because the fertility rates for both high-income and low-income women have been declining for three decades. Furthermore, Rank (1989) finds that women on welfare have a fertility rate lower than that of the general population and their likelihood of giving birth declines the longer they are on welfare.

One causal pattern appears in all three systems: Earnings and the unemployment rate simultaneously cause each other. Causality flowing from the unemployment rate to earnings supports the cost-of-job-loss model. Causality flowing from earnings to the unemployment rate has more to do with labor market theory than the welfare caseload. Standard analysis predicts that when wages (and thus earnings) rise fewer labor units will be hired.

Two predicted patterns find no support. None of the systems produce evidence that the unemployment rate causes the welfare caseload. Thus, the macroeconomic model receives no direct support from this analysis. ${ }^{11}$ There is also no evidence that welfare benefits cause the unemployment rate as the work disincentive model predicts.

The two systems which measure welfare benefits solely as AFDC benefits indicate that the caseload and earnings simultaneously cause each other. That causality runs from earnings to the caseload supports the human capital model. However, when the combined AFDC and Food Stamps benefit per recipient is used to measure welfare benefits earnings and the caseload do not appear to be causally related. Instead benefits appear to cause earnings. This latter result is consistent with the cost-of-job-loss model. Perhaps the AFDC benefit by itself is hardly adequate to replace lost earnings, but a package of benefits is.

This "mixed bag" of findings suggests that researchers and policy-makers should be cautious in choosing one model of the welfare caseload over another. Our results suggest that the relationships among the welfare benefit, caseload, and labor market conditions are too complex to be fully captured by any one of the basic models. Instead a number of the various models appear to be important in the explanation of welfare caseloads. Previous research on welfare 
programs has focused primarily on the work disincentive and human capital models. These findings suggest that perhaps the cost-of-job-loss model merits an equal amount of attention.

\section{Notes}

1. Darity and Myers (1984) and Smith (1993) are the exceptions. The former paper uses the Granger causality test to determine whether welfare benefits cause female-headed families among blacks. The latter paper uses the Granger causality concept to test whether AFDC benefits (U.S. average) cause the AFDC caseload. Both analyses rely on techniques for lag selection which restrict all variables in the system to the same lag length.

2. The increase in women's welfare participation also resulted from increased eligibility due to lower tax rates on benefits.

3. Researchers often identify the median voter as the voter with the median income. See Inman (1978).

4. For a review of the causality literature see Pierce and Haugh (1977).

5. National AFDC policy has changed over the sample period. Most importantly, in 1981 the Omnibus Budget Reconciliation Act (OBRA) made three significant changes: 1. Absolute income ceilings were instituted, reducing the eligibility of the working poor; 2 . The income disregard was reduced; and 3. Ceilings on work related deductions were set. These changes removed approximately 400,000 families from the national AFDC rolls. This simultaneous reduction of benefits and caseloads could increase the likelihood that benefits will appear to Granger-cause caseloads (or the reverse pattern).

To test whether this policy change caused a shift in the models' parameters a dummy variable denoting post-OBRA observations were included in each equation and the systems were then re-estimated. In the first system (by case) two of the post-OBRA dummies are statistically significant. Not surprisingly, the post-OBRA dummy in the benefits equation is significant (at the $10 \%$ level) and negative. The dummy in the earnings equation is significant at the $5 \%$ level and positive. These potential shifts suggest some caution should be taken in interpreting the results of this system.

In the second system (by recipient) only one post-OBRA dummy, in the unemployment equation, is significant at the $10 \%$ level. In the final system (combined benefits per recipient) none of the post-OBRA dummies are statistically significant. In these two systems structural shifts do not seem to be a problem.

6. These are the average monthly benefits in the AFDC-Regular program and do not include benefits in the AFDC-Unemployed Parent program. Michigan's maximum AFDC benefit tends to exceed the national average slightly both in nominal and real terms.

7. Studies of welfare commonly use the combined AFDC and Food Stamp benefit to measure total cash welfare benefits as Food Stamps are generally considered to be "near cash." Hamermesh and Johannes (1985) find that Food Stamps substitute one-for-one with M1, although the marginal propensity to consume out of Food Stamp coupons exceeds that of ordinary income. Moffitt (1989) examines the 1982 "cash out" of the Food Stamps program in Puerto Rico and finds that Food Stamps in this jurisdiction were equivalent to cash.

8. Ideally $B E N$ would be measured by the entire package of cash and in-kind benefits available. However, some components of this package, e.g. medical care and other in-kind benefits, are very difficult to measure. Due to the difficulty of determining the value of these benefits to recipients and the lack of complete series on all benefits we use the dominant cash benefit available, AFDC. We use the national CPI-U to convert all nominal values into real terms. 
9. The detailed results of the lag selection regressions are available from the authors upon request.

10. The Michigan Department of Social Services does not have data on Food Stamp benefits per case.

11. One could argue that there is weak, indirect evidence in support of the macroeconomic model. In systems (5) and (6) the unemployment rate causes earnings, and earnings in turn cause the caseload.

\section{References}

Anderson, G. (1987). Welfare programs in the rent-seeking society. Southern Economic Journal 54(2): 377-386.

Bassi, L. (1990). Employment and welfare participation among women. Economic Inquiry 28: 222-238.

Bowles, S. (1985). The production process in a competitive economy: Walrasian, Neo-Hobbesian, and Marxian models, American Economic Review, 75(1): 16-36.

Caines, P., Keng, C. and Sethi, S. (1981). Causality analysis and multivariate autoregressive modelling with an application to supermarket sales analysis, Journal of Economic Dynamics (August): 267-298.

Choi, B. (1992). ARMA Model Identification, New York: Springer-Verlag.

Conover, W. and Iman, R. (1982). Analysis of covariance using the rank transformation, Biometrics, 38: 715-724.

Danziger, S., Haveman, R. and Plotnick, R. (1981). How income transfer programs affect work, savings, and the income distribution: A critical review. Journal of Economic Literature 19: 975-1028.

Darity, W. and Myers, S. (1984). Does welfare dependency cause female headship? The case of the black family, Journal of Marriage and the Family (November): 765-779.

Dickey, D. and Fuller, W. (1981). Likelihood ratio statistics for autoregressive time series with a unit root, Econometrica 49: 1057-1063.

Duncan, G. (1984). Years of Poverty, Years of Plenty, Institute for Social Research: Ann Arbor, Michigan.

Franklin, B. (1776). On the Price of Corn, and the Management of the Poor.

Geweke, J. and Meese, R. (1981). Estimating regression models of finite but unknown order, International Economic Review 22: 55-70.

Granger, C.W.J. (1969). Investigating causal relations by econometric models and cross-spectral methods. Econometrica 34: 424-438.

Hamermesh, D. and Johannes, J. (1985). "Food Stamps as money: The macroeconomics of a transfer program," Journal of Political Economy 93: 205-213.

Holmes, J. and Hutton, P. (1988). A functional-form, distribution-free alternative to parametric analyses of Granger causal models, Advances in Econometrics 7: 211-225.

Holmes, J. and Hutton, P. (1992). A new test of money-income causality, Journal of Money, Credit, and Banking 23(3): 338-355.

Inman, R. (1978). Testing political economy's "as if" proposition: Is the median voter really decisive? Public Choice 33: 45-65.

Leffler, K. (1978). Minimum wages, welfare, and wealth transfers to the poor. Journal of Law and Economics 201(2): 476-494.

Moffitt, R. (1983). An economic model of welfare stigma, American Economic Review 73: $1023-1035$. 
Moffitt, R. (1987). Historical growth in participation in Aid to Families with Dependent Children: Was there a structural shift? Journal of Post Keynesian Economics IX(3): 347-363.

Moffitt, R. (1989). Estimating the value of in-kind transfers: The case of Food Stamps, Econometrica 57(2): 385-409.

Murray, C. (1984). Losing Ground: American Social Policy, 1950-1980. Basic Books, New York.

Nelson, C. and Kang, H. (1984). Pitfalls in the use of time as an explanatory variable in regression, Journal of Business and Economic Statistics 2: 73-82.

Nelson, C. and Plosser, C. (1982). Trends and random walks in macroeconomic time series: Some evidence and implications, Journal of Monetary Economics 10: 139-162.

Olejnik, S. and Algina, J. (1985). A review of nonparametric alternatives to analysis of covariance, Evaluation Review 9: 51-83.

Olson, M. (1971). The Logic of Collective Action: Public Goods and the Theory of Groups: Harvard University Press, Cambridge.

Pierce, D. and Haugh, L. (1977). Causality in temporal systems: Characterizations and a survey. Journal of Econometrics 5: 265-293.

Rank, M. (1989). Fertility among women on welfare: Incidence and determinants. American Sociological Review 54(2): 296-304.

Sims, C. (1972). Money, income and causality. American Economic Review 62: 540-552.

Schor, J. and S. Bowles (1987). Employment rents and the incidence of strikes. Review of Economics and Statistics 69(4): 177-184.

Smith, P. (1993). Welfare as a cause of poverty: A time series analysis, Public Choice 75: 157-170. Thorton, D. and Batten, D. (1985). Lag-length selection and tests of Granger causality between money and income, Journal of Money, Credit, and Banking 17: 164-78.

\section{Appendix: Data Description}

1. Michigan's monthly average unemployment rate (unadjusted): Current Population Survey Estimates for Michigan, Michigan Employment Security Commission.

mean $=9.23$ s.d. $=2.75 \min =4.3 \quad \max =17.3$

2. Average weekly real earnings of Michigan manufacturing workers: Michigan Hours \& Earnings Statistics, v. 1, Bureau of Research and Statistics, Michigan Employment Security Commission. mean $=\$ 482.74$ s.d. $=\$ 32.62 \min =\$ 410.25 \max =\$ 582.73$

3. Average monthly real benefit in the Michigan AFDC-Regular program: Monthly Trend Report of Key DSS Statistics, Michigan Department of Social Services, Data Reporting Section.

Per case:

mean $=\$ 444.09$ s.d. $=\$ 85.25 \min =\$ 267.97 \max =\$ 588.81$

Per recipient:

mean $=\$ 144.11$ s.d. $=\$ 19.25 \min =\$ 94.10 \max =\$ 183.76$

4. Real value of Michigan's average monthly AFDC-Regular benefit plus Food Stamps benefits per recipient: Monthly Trend Report of Key DSS Statistics, Michigan Department of Social Services, Data Reporting Section.

mean $=\$ 151.33$ s.d. $=\$ 51.57 \min =\$ 57.40 \quad \max =\$ 240.37$

5. CPI-U, city average, all items, $1982=1984=100$ : C.P.I. Detailed Report, January 1992, U.S. $\approx$ Department of Labor, Bureau of Labor Statistics. 